\title{
Research on Behavior Incentives of Prefabricated Building Component Manufacturers
}

\author{
Pinbo Yao ${ }^{1}(1)$ and Hongda Liu ${ }^{1,2, *}$ \\ 1 School of Management, Shanghai University, Shanghai 200444, China; yaopinbo@shu.edu.cn \\ 2 School of Economics and Management, Tongji University, Shanghai 200092, China \\ * Correspondence: liuhoda@shu.edu.cn
}

Citation: Yao, P.; Liu, H. Research on Behavior Incentives of Prefabricated Building Component Manufacturers. Information 2021, 12, 284. https:// doi.org/10.3390/info12070284

Academic Editor: M. Omair Shafiq

Received: 10 June 2021

Accepted: 14 July 2021

Published: 17 July 2021

Publisher's Note: MDPI stays neutral with regard to jurisdictional claims in published maps and institutional affiliations.

Copyright: (c) 2021 by the authors. Licensee MDPI, Basel, Switzerland. This article is an open access article distributed under the terms and conditions of the Creative Commons Attribution (CC BY) license (https:// creativecommons.org/licenses/by/ $4.0 /)$.

\begin{abstract}
Based on the positive externalities of prefabricated buildings, this paper constructs an evolutionary game model between the government and material component vendors and analyzes the changes in the behavior of the government and component vendors in different stages of the advancement of prefabricated buildings. Based on data modeling and equation prediction analysis, it can be found that the expansion of the incremental cost of construction at the initial stage inhibits the enthusiasm of the government. Thus, the government's incentive behavior effectively affects the behavior of component vendors, and fiscal taxation and punishment policies will promote component vendors to provide prefabricated components. In the development stage, the government's fiscal policy influence that weakens and affects component vendors' behavior mainly comes from the incremental costs and benefits of components. Additionally, the difference between the builder's incremental cost and the sales revenue narrowed. At this time, the behavior prediction of both parties tends to be steady. In the mature stage, prefabricated buildings will mainly rely on market forces, and the government can gradually withdraw from the market. The cost variable tends to be lower, and it can be predicted that component vendors tend to supply components, while the government tends to restrict policies.
\end{abstract}

Keywords: prefabricated building; evolutionary game; positive externalities; progression stage

\section{Introduction}

Prefabricated building refers to a building where a large number of on-site operations in traditional construction methods are transferred to the factory. The walls, beams, slabs, columns, stairs, and other components in the building are prefabricated in the factory and transported to the construction site for assembly. This factory-based production method has significant advantages in dealing with the harsh off-site working environment, waste of energy materials, and pollution to the surrounding environment. It is in line with the development direction of green and energy-saving buildings. Prefabricated buildings can bring additional benefits to society, but this cannot compensate for them. This positive externality effect will lead to market failure. Only by market regulation is it difficult for the government to increase market enthusiasm without proper management and incentives. [1]. On 30 September 2016, the General Office of the State Council issued the "Guiding Opinions on Vigorously Developing Prefabricated Buildings". As an important measure to promote the supply side structural reform and the development of new urbanization, the prefabricated building method has developed fully. Through the prefabricated building market survey, it is found that public rental housing projects and demonstration projects mandated by the state account for a large proportion, while the proportion of civil, residential projects is not high. In some places, to achieve the national target of $30 \%$, only a few parts use fabricated components, far from reaching the ideal state. The reason is that industrialized production methods have increased costs in the early stage of the development of prefabricated buildings, and the increase in component costs is one of the 
main factors that increase the cost of prefabricated buildings. The behavior of material component manufacturers to provide ordinary building materials or components affects the development of prefabricated buildings [2].

In research to promote the development of prefabricated buildings, Chen (2018) [3] constructed a game model between the government, developers, and consumers from the perspective of the demand side and supply side of prefabricated building development and concluded that the government's direct macro-control affects prefabricated buildings. Development under the influence of many stakeholders is a good way for the government to indirectly encourage the development of prefabricated buildings through the perspective of regulatory component suppliers. The government's regulation of relevant stakeholders is shown in Figure 1. The government can directly control the development direction of the construction market from the supply side and the demand side by regulating developers' and consumers' behaviors or indirectly regulating development by regulating the component suppliers. The behavior of the business, in turn, affects the direction of the construction market. In an era of vigorously developing prefabricated buildings, the government can adopt active policies to develop prefabricated buildings and adopt negative policies to restrain the development of traditional cast-in-place buildings.

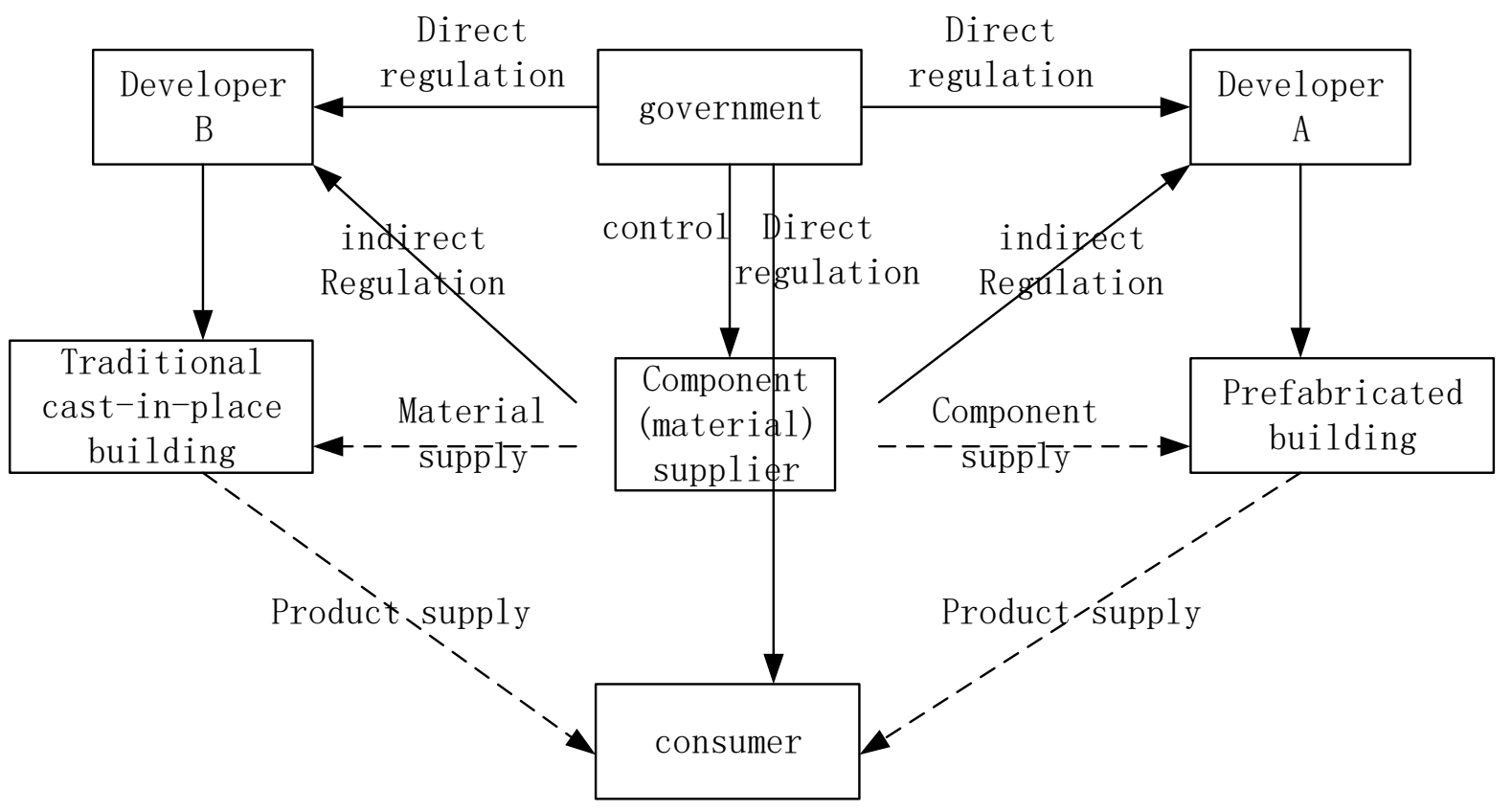

Figure 1. Stakeholder regulation diagram.

\section{Literature Review}

As a key development direction that the country vigorously promotes, prefabricated buildings have been studied by many scholars. Chen (2017) [4] used the evolutionary game method to analyze the influence of different behaviors between the government and the developer in promoting prefabricated buildings and pointed out that the government should take measures, and the developers should carry out technological innovation, to promote development. Wang (2019) [5] analyzed the government subsidies' perspective on what policies the local government should implement to enable construction units to cooperate better with the construction of prefabricated buildings. Li (2020) [6] pointed out that the stability of the prefabricated building development system is related to cost increase, income, and risk, which will affect the behavior of the government and developers. Zhou (2019) $[7,8]$, starting from the external benefits of prefabricated buildings, using bargaining games to analyze the external benefit distribution between the government, developers, and consumers, established a quantitative analysis model and determined quantitative 
indicators of environmental benefits. Through case analysis, it is determined that distributing the external benefits of prefabricated buildings to the government, developers, and consumers in proportions of $38 \%, 35 \%$, and $27 \%$, respectively, is the best distribution of benefits and stimulates the enthusiasm of relevant personnel. Feng (2017) [9] used the evolutionary game method to analyze the game behavior between component vendors, analyzed the behavior change between component vendors under the two additional incentives, and punishments, and concluded that an effective reward and punishment mechanism would promote a win-win cooperation situation. Han (2017) [10] established a Cournot-Stackelberg comprehensive game model based on the perspective of the supply chain in the market equilibrium of the independent manufacturing of prefabricated components and outsourcing in two different situations, analyzed the profit level of the supply chain companies in changes in the scale of the prefabricated construction market under different behavioral decisions, and put forward suggestions to strengthen the integration of the industrial chain and strengthen the guidance of parts factories. The application of BIM technology in prefabricated buildings can improve the consistency of the system coordination of prefabricated building facilities and provide a reference for the design of prefabricated building components. Tang (2019) [11] pointed out that in order to improve the adoption rate and application level of BIM in facility management, the evolutionary game theory to be used to analyze the different evolution situations in the cooperative behavior system, and it was concluded that the behavioral strategy selection of a single company will be affected by the behavioral decisions of other companies in the group. The main reason for the limited development of prefabricated buildings is that all the industry stakeholders that provide prefabricated building construction have not been guaranteed their profits when facing emerging industries. From previous studies, we have found that factory-based prefabrication can effectively reduce environmental pollution and improve people's quality of life. This is also the reason why the country vigorously promotes prefabricated buildings. From the perspective of the government, the country, and society, the social benefits generated by the factory-based production method are higher than the costs of the stakeholders of the producer; therefore, the industry has positive externalities.

Through the analysis of the literature mentioned above, we found that (1) few scholars have combined the development process of prefabricated buildings with the government's macro-control. At different stages of the development of prefabricated buildings, the government should adopt different incentive policies for component suppliers to respond to the development of prefabricated buildings. The positive externality in the process internalizes the externality, also known as Pigou, means [12]. (2) When researching the stakeholders involved in assembled buildings, more articles analyze the gaming behavior between the government and developers without analyzing the impact of advances in component production technology on the development of assembled buildings from the perspective of component traders (material suppliers). Therefore, in the context of positive externalities, this article hypothesizes the development process of prefabricated buildings [13] and establishes an evolutionary game model to analyze how the government should adopt policies to stimulate the behavior of component suppliers and indirectly promote prefabricated buildings at different development stages.

\section{Theory and Methodology}

\subsection{Analysis of Positive Externalities}

The construction of prefabricated buildings can provide not only direct economic benefits to relevant stakeholders but also has significant advantages in protecting the environment and saving resources. Therefore, it exhibits significant positive externalities, and the social benefits brought by it are recognized. The incoming incremental costs need to be borne by the relevant stakeholders. As the main undertaker, component manufacturers are the main bearers. In the initial stage of prefabricated construction, the marginal corporate benefits are less than the marginal social benefits. From the principles of economics, we know that when the marginal corporate benefit is less than the marginal 
social benefit, the allocation of social resources cannot reach the Pareto optimum, and the behavior of component vendors hinders the development of prefabricated buildings [14].

According to the analysis in Figure 2, point A represents the intersection of the marginal corporate benefit curve and the supply curve when the company does not consider external benefits. At this time, the number of components produced by the component manufacturer is Q1, and the production cost is C2; when external benefits are considered, the supply curve and the marginal social benefit curve intersect at point $B$. Currently, the society's demand for components is Q2, the production cost is C3, and the incremental cost $\Delta \mathrm{C}$ is generated. When a component company makes a production decision, it only considers its benefits, does not consider social benefits, and finally positions its output at Q1. At this time, from the perspective of society as a whole, it has not reached the Pareto optimum. If the overall social benefits are considered optimal, component companies must increase output to Q2, at which time the cost will be compressed to C1. In the early stage of developing prefabricated buildings, it is difficult to reduce the cost of immature technology. Government policy support is needed to internalize the social benefits of externalities, to improve the output of component manufacturers, and achieve the best social benefits.

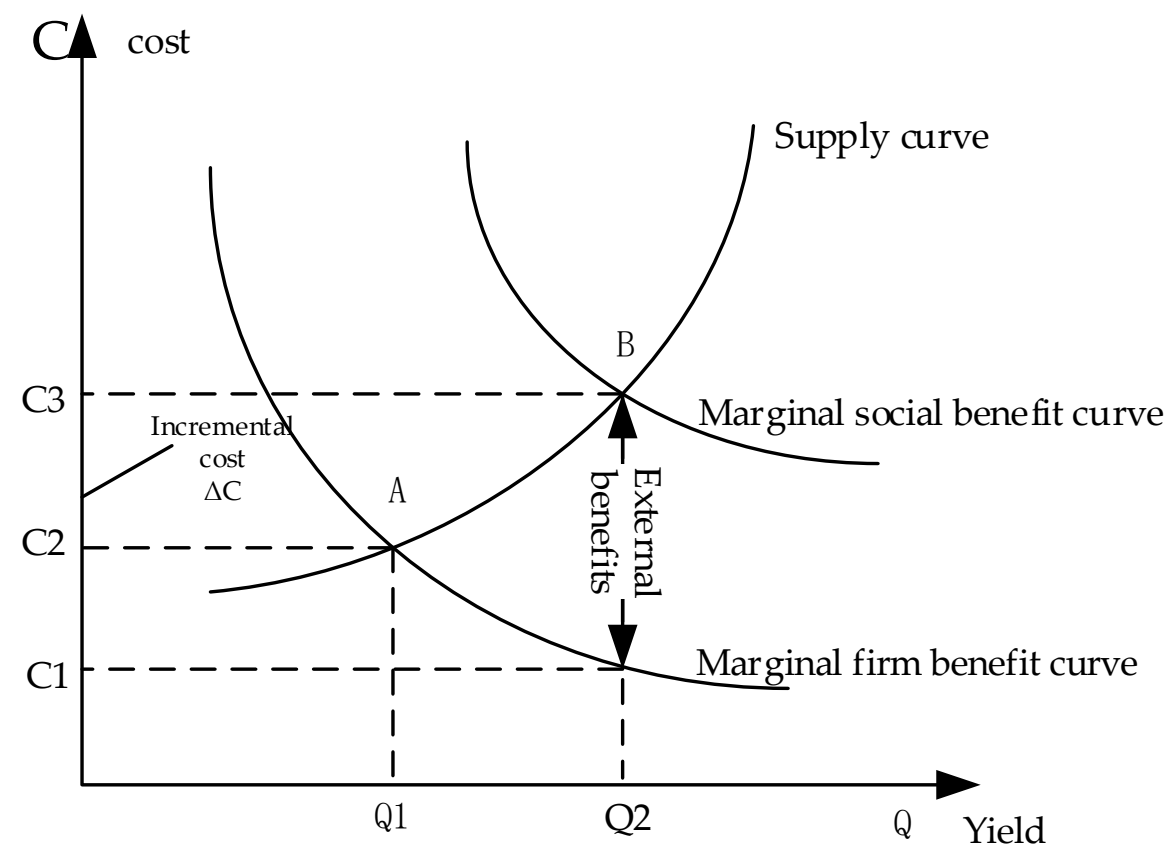

Figure 2. Externality analysis of prefabricated buildings.

\subsection{Analysis of Development Stages}

Externality reduces the market efficiency of prefabricated buildings and hinders the promotion and development of prefabricated buildings. Zheng [15] pointed out in the post-evaluation process of studying green buildings that the development of green buildings should aim at solving externalities, making up for market failures, and improving efficiency, and divides the target efficiency into conversion efficiency, operational efficiency, and financial efficiency. Based on the above research, according to the development characteristics of prefabricated buildings, the development process is divided into three stages, as shown in Figure 3, start, development, and maturity. 


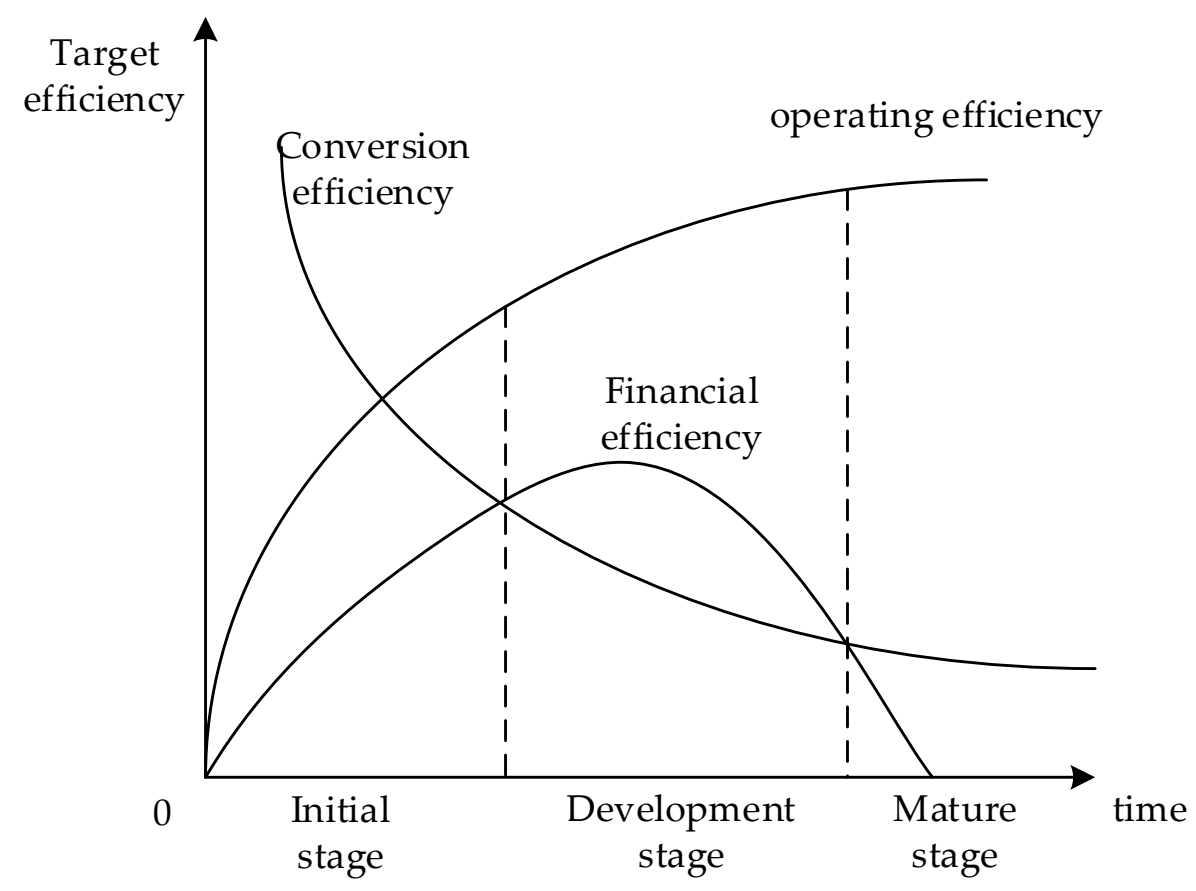

Figure 3. Analysis of the development stage of prefabricated buildings.

Conversion efficiency refers to the development of more and more prefabricated buildings. The conversion efficiency of ordinary cast-in-place buildings to prefabricated buildings will become lower and lower over time. It also shows that the efficiency of the internal transformation of externalities increases with prefabricated buildings. With the increase in the number of buildings, the pressure from externalities on component vendors is gradually distributed to the general public, the relevant stakeholders, and the conversion efficiency is gradually decreasing; the operating efficiency reflects the maturity of the development of prefabricated buildings, and the operating efficiency is marginal with a time decrease but has been increasing, indicating that the development of prefabricated buildings is gradually maturing; and the financial efficiency measures the rewards that stakeholders obtain from prefabricated buildings, including government fiscal tax subsidies and other incentives. With the gradual maturity of the market, the "market failure" will gradually disappear, the market will determine the final transformation, and financial efficiency will first increase and then decrease.

In the initial stage, the operating efficiency increased rapidly, and the conversion efficiency was higher than the financial efficiency. At this time, the government adopted active incentive policies. The component manufacturers mainly provided traditional cast-in-place materials and began to try to provide prefabricated components. The production cost of prefabricated components was high. In the development stage, operational efficiency is further improved, technology development costs are reduced, and financial efficiency is higher than the conversion efficiency. At this time, the government adopts a prudent incentive policy, component vendors mainly provide components, and prefabricated buildings are well developed. In the mature stage, the operating efficiency gradually rises but the trend is flat, the technology is more mature, the cost is reduced, and the financial efficiency declines gradually to zero. At this time, the government withdrew and the market played the role of resource allocation.

\subsection{Evolutionary Game Models}

In the course of repeated games, when all the information is not available, both sides of the game will adjust their strategies at the margins in their interest. After improving their situation and their choice of behavior, they will eventually approach equilibrium, and no party will change its behavioral choices. The strategy adopted by the players at this point 
is the evolutionary stabilization strategy, a process known as an evolutionary game [9]. The evolutionary game consists of the following two core concepts: the evolutionary stabilization strategy and the replicator dynamics equation. The basic idea of the evolutionary stability strategy is that when a group chooses a way of behaving without mutating, this must be the way that will lead to higher payments, and as the evolutionary game continues, the most mutated group will disappear. The original group chooses the evolutionarily stable strategy, and the equilibrium, in this case, is known as the evolutionarily stable equilibrium. Replicator dynamics: the difference between the utility gained by adopting a strategy and the average utility is the growth rate of the number of people choosing that strategy. If the utility gained by a group by adopting a strategy exceeds the average utility of the group as a whole, then the number of people adopting that strategy will increase. If the group's utility from adopting a strategy is lower than the overall average utility, then the number of people adopting the strategy will decrease [16].

\section{Model Assumptions, Construction, and Analysis}

\subsection{Basic Assumptions of the Model}

Based on the investigation and analysis of the actual situation, this paper assumes that the two parties of the evolutionary game are the government and prefabricated building component business groups. Government groups refer to the various government organizations involved in the construction process of prefabricated buildings' whole life construction cycle. The government groups can be divided into central government and local government from government attributes, power size, and hierarchical relationship [16]. From the perspective of the life cycle of construction projects, the government can be divided into urban planning government departments, land management government departments, housing, urban-rural construction government departments, finance and taxation government departments, environmental protection government departments, safety construction government departments, etc. The government involved in the development, design, construction, and environmental protection of prefabricated buildings is itself a group organization, not an individual. For different types of governments, the behavioral strategies for prefabricated building component manufacturers are different. In order to promote the construction of prefabricated buildings, some governments will take some positive measures to encourage development or take punitive measures to curb the environmental pollution caused by the development of traditional buildings. Another part of the government department showed no concern about the behavior of component vendors or implement a mere formal incentive, such as verbal praise. The component merchant group refers to the producers of the prefabricated building components produced during the development of the market economy. With the development of science and technology and innovation, the scale, the mastery of core technology, and the production cost vary among enterprises, which has created groups of enterprises with different competitiveness. When facing the new construction model that the government actively promotes development, various enterprise groups show different attitude types, mainly divided into actively responding to the government's call to produce components and not producing components to provide ordinary building materials.

The behavioral strategy choices of the government and the material component suppliers influence each other [17], which is an evolutionary game process. Based on the theoretical characteristics of the two-party evolutionary game [18], the following assumptions are made:

Hypothesis 1 (H1). The government and the component business represent two different game groups, they will not be fully rational, and both are bounded rationality. The main goal of the government is to promote prefabricated buildings, and the main goal of component manufacturers is to make profits. Both will continue to change their strategies over time; 
Hypothesis 2 (H2). Component vendors have the following two choices: provide common building materials and provide fabricated components, among which the fabricated components are not distinguished by assembly rate. The government first formulates incentive policies to promote prefabricated buildings, including the implementation of effective incentive policies, such as $R \mathcal{E} D$ subsidies, tax reductions, exemptions, and other substantive incentive policies, such as tax increases and environmental fines. Other incentive policies that are mere formalities or do not implement incentive policies will be treated as such. Treated as no incentive;

Hypothesis 3 (H3). The two strategies that the government can choose are incentive $(x)$ and nonincentive $(1-x)$; the two strategies that component vendors can choose are provide prefabricated components $(y)$ and provide common materials $(1-y)$.

\subsection{Variable Selection and Model Construction}

$E_{1}$ : The net income obtained by the component supplier from providing ordinary building materials;

$E_{2}$ : The government's income when the component supplier provides ordinary materials;

$E_{3}$ : Incremental income obtained by component vendors providing the fabricated components;

$E_{4}$ : The government's incremental benefits due to the popularization of prefabricated buildings;

$C_{1}$ : The component supplier provides the incremental cost of the fabricated component;

$C_{2}$ : Losses caused by unresponsive government incentives;

$B$ : Government subsidies for component vendors who actively respond to policies to develop new technologies;

$F$ : The government's punishment for component vendors who do not actively respond to the policy.

Based on the setting of the above variables, a game matrix between the government and component vendors is constructed, as shown in Table 1.

Table 1. Game payment matrix between the government and material component suppliers.

\begin{tabular}{cccc}
\hline & & \multicolumn{2}{c}{ Government } \\
\cline { 3 - 4 } & & Incentive $(x)$ & Non-Incentive $(1-x)$ \\
\hline \multirow{3}{*}{ Component quotient } & $\begin{array}{c}\text { Provide prefabricated } \\
\text { components }(y)\end{array}$ & $\begin{array}{c}E_{1}+E_{3}-C_{1}+B \\
E_{2}+E_{4}-B\end{array}$ & $\begin{array}{c}E_{1}+E_{3}-C_{1} \\
E_{2}+E_{4}\end{array}$ \\
\cline { 2 - 4 } & Provide common & $E_{1}-F$ & $E_{1}$ \\
& materials $(1-y)$ & $E_{2}-C_{2}+F$ & $E_{2}$ \\
\hline
\end{tabular}

\subsubsection{Expected Benefits of Component Vendors}

The expected benefits of the component provided by the component supplier are as follows:

$$
\mu_{11}=x\left(E_{1}+E_{3}-C_{1}+B\right)+(1-x)\left(E_{1}+E_{3}-C_{1}\right)
$$

The expected benefits of component vendors providing common materials are as follows:

$$
\mu_{12}=x\left(E_{1}-F\right)+(1-x) E_{1}
$$

The average expected return of component business is as follows:

$$
\mu_{1}=y \mu_{11}+(1-y) \mu_{12}
$$


The copy dynamic equation of the component supplier is as follows:

$$
\begin{gathered}
F^{\prime}(y)=\frac{d y}{d t}=y\left(\mu_{11}-\mu_{1}\right) \\
=y(1-y)\left(\mu_{11}-\mu_{12}\right) \\
=y(1-y)\left[x(B+F)+E_{3}-C_{1}\right]
\end{gathered}
$$

Let $F^{\prime}(y)=0$, obtain $y_{1}=0, y_{2}=1, x^{*}=\frac{C_{1}-E_{3}}{B+F}$; at this time, the game is in a stable equilibrium state. The ratio of component suppliers to provide the fabricated components and common materials is in a stable and balanced state.

\subsubsection{The Government's Expected Income}

The expected benefits of government incentive policies are as follows:

$$
\mu_{21}=y\left(E_{2}+E_{4}-B\right)+(1-y)\left(E_{2}-C_{2}+F\right)
$$

The expected benefits when the government does not adopt incentive policies are as follows:

$$
\mu_{22}=y\left(E_{2}+E_{4}\right)+(1-y) E_{2}
$$

The average expected income of the government is as follows:

$$
\mu_{2}=x \mu_{21}+(1-x) \mu_{22}
$$

The government's replication dynamic equation is as follows:

$$
\begin{gathered}
F^{\prime}(x)=\frac{d x}{d t}=x\left(\mu_{21}-\mu_{2}\right) \\
=x(1-x)\left(\mu_{21}-\mu_{22}\right) \\
=x(1-x)\left[y\left(C_{2}-B-F\right)-C_{2}+F\right]
\end{gathered}
$$

Let $F^{\prime}(x)=0$, obtain $x_{1}=0, x_{2}=1, y^{*}=\frac{C_{2}-F}{C_{2}-B-F}$; at this time the proportion of the government adopting incentive policies and not adopting incentive policies is in a stable equilibrium.

In summary, there are five local equilibrium points of the game matrix composed of the government and the component merchants, which, respectively, are $\mathrm{O}(0,0), \mathrm{A}(1,0)$, $\mathrm{B}(0,1), \mathrm{C}(1,1)$, and $\mathrm{D}\left(\frac{C_{1}-E_{3}}{B+F}, \frac{C_{2}-F}{C_{2}-B-F}\right)$.

\subsection{Analysis of Model Results}

According to Hirshleifer theory, the Jacobian matrix can be used to analyze the local stability of the evolutionary system at the above five equilibrium points. According to the dynamic replication equation, the Jacobian matrix is obtained [19].

$$
J=\left[\begin{array}{ll}
\frac{\partial F(x)}{\partial(x)} & \frac{\partial F(x)}{\partial(y)} \\
\frac{\partial F(y)}{\partial(x)} & \frac{\partial F(y)}{\partial(y)}
\end{array}\right]=\left[\begin{array}{cc}
A & B \\
C & D
\end{array}\right]
$$

Then, the trace of the matrix is $\operatorname{tr} J=A+D$.

The determinant of the Jacobian matrix and the sign of trace can determine whether the above five equilibrium points are stable strategies (ESS). When $\operatorname{tr} J<0$ and $\operatorname{det} J=|J|>0$ are satisfied, the equilibrium point reaches a stable state and finally becomes a stable strategy.

Based on dividing the target efficiency of the prefabricated buildings into conversion efficiency, operation efficiency, and financial efficiency, and according to the analysis of the development stage, the following conclusions are drawn:

In the initial stage, from the perspective of component vendors, a lack of experience and the immaturity of technology directly lead to the incremental cost of providing components greater than the incremental benefits of their sales, namely $C_{1}>E_{3}$. The government, when designing tax and other fines policies, should consider that the costs incurred by its 
incentives and the costs incurred in environmental governance can be compensated, that is $C_{2}<F$. At the same time, it is also necessary to ensure that the subsidy provided can make the overall profit of the component business positive and stimulate the enthusiasm of the component business, that is $C_{1}-E_{3}+B>0$. Based on the above hypothesis, when $x>x^{*}$ and $F^{\prime}(y)<0, y=1$ is an evolutionary stable equilibrium solution; when $x<x^{*}$ and $F^{\prime}(y)<0, y=0$ is an evolutionary stable equilibrium solution. In the same way, it can be concluded that when $y>y^{*}$ and $y<y^{*}$, the evolutionary stable equilibrium solution is $x=1$ and $x=0$. In the initial stage, the replication dynamic phase diagram of the government and component vendors is shown in Figure 4.

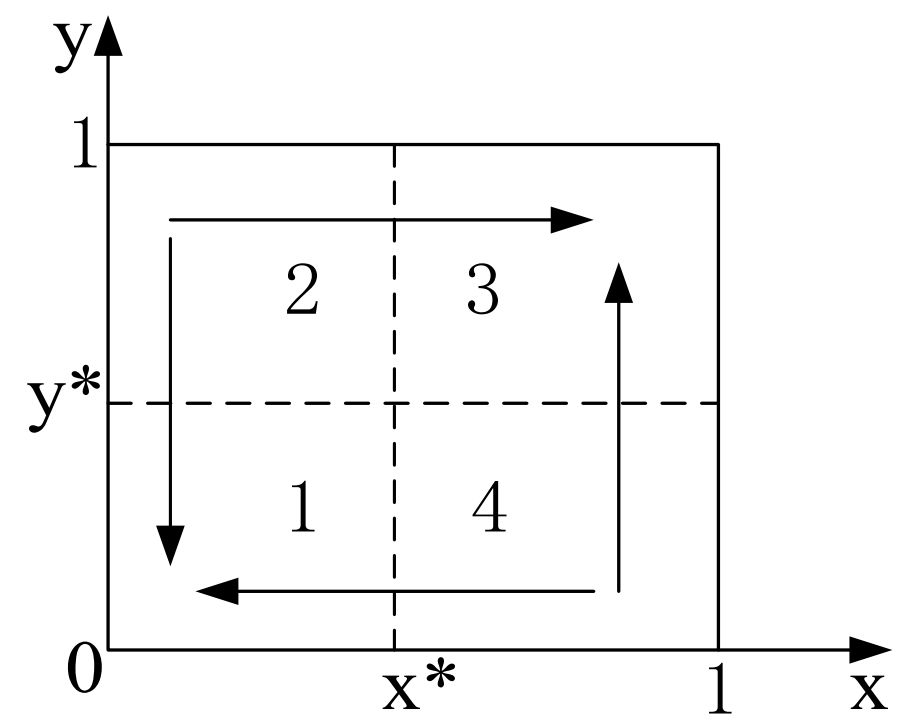

Figure 4. Copy the dynamic phase diagram in the initial stage.

The two stable equilibrium solutions are $(0,0)$ and $(1,1)$. The initial conditions determine the direction of evolution. When the initial conditions fall in area one, the evolutionary stability strategy is to provide ordinary materials and goverment no incentives, when the initial conditions fall in area two, the strategy is to provide components with incentives. Therefore, increasing the area of area three will be more conducive to the development of prefabricated buildings. At this time, the value should be reduced $(x *, y *)$. The solution strategy is to reduce the incremental costs, increase the incremental benefits, and strengthen the incentives.

In short, in the initial stage of prefabricated buildings, due to the immaturity of external conditions such as technology, management, and policies, the development of prefabricated buildings is restricted by factors such as cost. When facing the choice of producing components and providing traditional materials, the manufacturers of prefabricated building components face differences in costs and differences in profits. The vast majority of component merchants will choose to provide traditional materials, while a small number of component merchants that respond to the government's call will provide components to promote the development of prefabricated buildings. As the market develops, manufacturers that provide components will find that the profits generated by the provision of components are less than the profits generated by the provision of traditional materials in the early stages of development. The strategic choices gradually shift from providing components to providing traditional materials. At this time, the government had to encourage component manufacturers to produce components to promote prefabricated buildings in the face of the environmental pollution caused by traditional buildings. Therefore, in the early stage of development, if there are no government active measures, the component suppliers who choose to provide components will gradually transform to providing traditional materials, and the development of prefabricated buildings will be 
hindered. The government's incentive policy of rewards and punishments is an effective means to break the barriers to the development of prefabricated buildings.

In the development stage, the incremental cost of the component business is still greater than the incremental income brought by the production and sale of components, but the difference between the two is relatively close, namely $C_{1}>E_{3}$. From the government's point of view, in the initial stage, strong incentive policies have prompted component vendors to provide components, and prefabricated buildings have been fully developed. At this time, the government's fiscal and taxation policies need to be slowed down to allow the market to play a certain role. Only use funds to control the industry, namely $C_{2}>F$. According to the above analysis, two situations can be drawn, namely $C_{2}>F+B$ and $C_{2}<F+B$. The two situations show the different degrees of the government's fiscal and taxation policy incentives, with the former more prominent in the role of market allocation. Based on the above assumptions, it can be concluded that the replication dynamic phase diagram of the government and component vendors in the development stage is that shown in Figure 5.
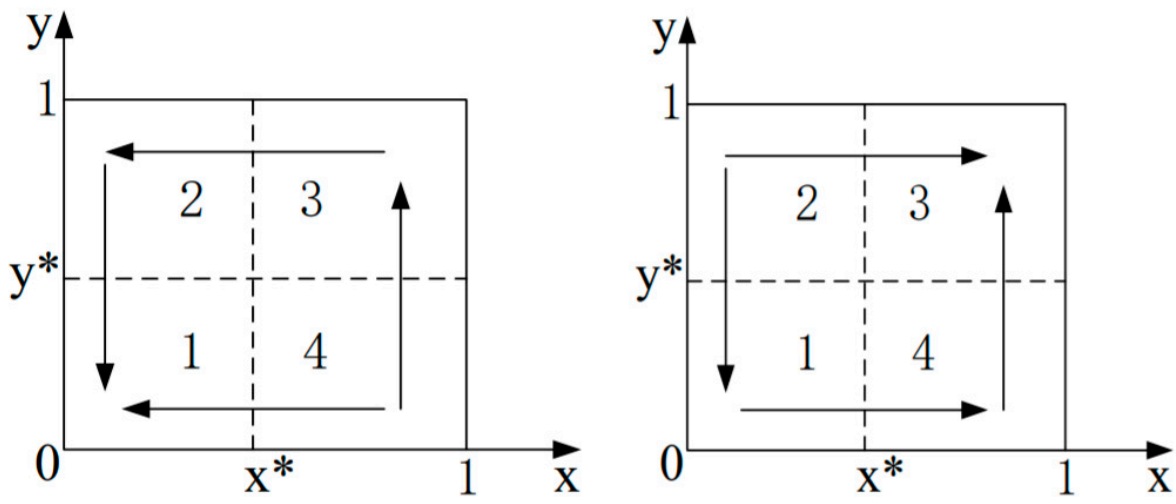

Figure 5. Copy dynamic phase diagram during development.

The analysis shows that the final evolutionary stable equilibrium point is determined by the component vendor behavior in the initial state. The government's incentive policy is in a "half-failure" state at this stage, and the entire industry is in a state of turbulence. Material component merchants who tend to prefabricated or traditional buildings will stick to their original choices. In this case, minimizing the value of $y^{*}$ will increase the proportion of components provided by the component supplier.

Therefore, in the development stage, prefabricated buildings are in a period of rapid development. The increase in experience and technology has reduced the production cost of components, and the profits of component manufacturers have gradually increased. According to Figure 3, the financial efficiency gradually increased to the maximum and began to show a downward trend. In contrast, the operating efficiency continued to rise, which shows that at this stage, the penetration of new technologies, new management models, and new development concepts has gradually replaced the effects of financial subsidies. According to the above analysis conclusions, the government's incentive strategy should be reduced from fiscal subsidies to fines. Cost is no longer the main factor that restricts component suppliers from providing components. The government does not need to provide too many subsidies to guide and encourage the production of components. Instead, the idea should be changed to increase the fines for providing traditional materials and components for environmental governance.

In the mature stage, the operating efficiency is further improved, the prefabricated building technology is more mature, the component cost is reduced, and the development of prefabricated buildings is more profitable than traditional cast-in-place buildings, that is $C_{1}<E_{3}$. The government has the following three choices at this stage: adopt strong incentive policies, adopt general strong measures, and not adopt incentive measures, 
namely $C_{2}<F \backslash C_{2}<F+B \backslash C_{2}>F+B$. The third party puts more emphasis on the role of market deployment. It can also be seen that the development of prefabricated buildings can be determined by the market at this moment, and the behavior of the government will not affect the development of final prefabricated buildings too much. The replication dynamic phase diagram of the government and component vendors based on the above assumptions is shown in Figure 6.
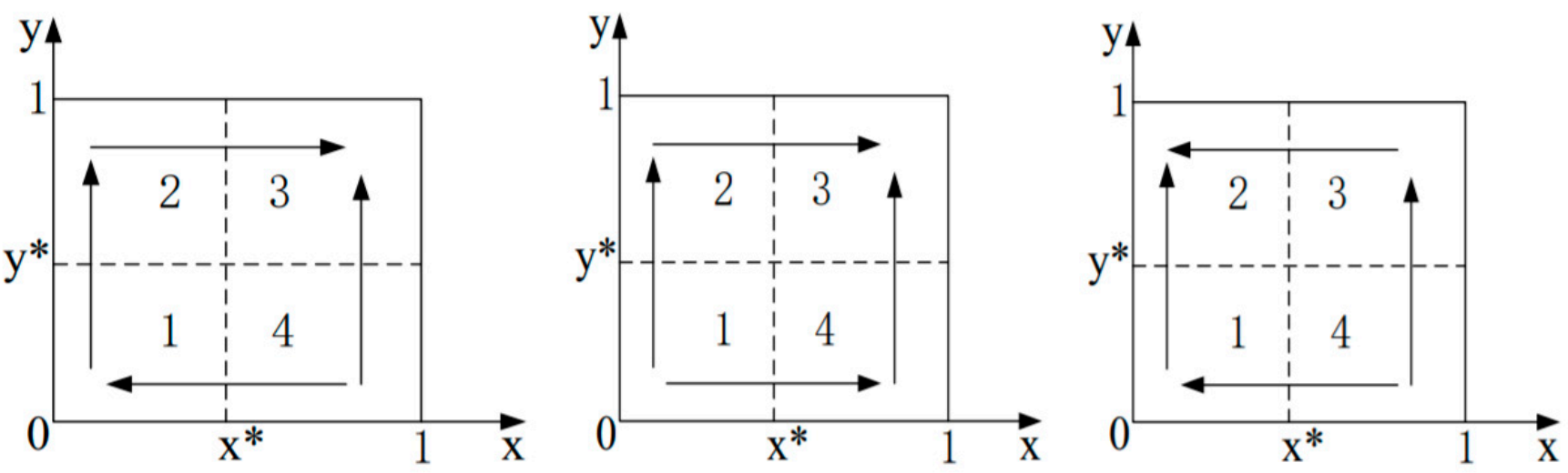

Figure 6. Replicating the dynamic phase diagram at the mature stage.

In the maturity stage, the profit of component suppliers will exceed the traditional way of providing materials, and the final result will be that component suppliers provide components. At this stage, the government's incentive policies will not play a role, the financial efficiency will be minimized, and the government will change from incentives to not adopting incentive policies. The suppliers that provide traditional materials in the development stage have the following two options: provide components or be eliminated. The role of the market has been brought into full play. Therefore, in the mature stage of industry development, the final stabilizing strategy for component vendors is to provide components. The government's policy change in the development of the entire industry sees the incentive policy of "subsidies as the main and fines supplemented" transformed into the restrictive policy of "fines as the main subsidy and supplemented". Finally, under the conditions of technological progress and cost reduction, it is transformed into a policy of "market supervision" by the market to play a role.

\section{Advancing Strategy Suggestions at Different Stages}

Based on the analysis of the externalities of prefabricated buildings, the government should play different roles to balance the benefits between relevant stakeholders at different stages of the development of prefabricated buildings. From the perspective of the stakeholders directly related to supply and demand [3], the government must not only encourage the transformation of the real estate development industry but also vigorously promote and actively guide consumers to purchase. From the perspective of material component suppliers, the problem can be solved fundamentally only by reducing incremental costs and increasing incremental revenue. According to the above analysis of evolutionary game behavior, governments at three different stages should adopt different incentive policies to promote component vendors to develop technology and provide components. At different stages, government incentives have different effects on the development of prefabricated buildings.

\subsection{Initial Stage}

It can be seen from Figure 4 that the evolutionary and stable equilibrium results of the government and component vendors in the initial stage of development are to provide components with incentives) and provide ordinary materials with no incentives. Combining Figure 3 shows that the initial transformation efficiency is the highest, and the govern- 
ment's effective incentive policies can internalize the external benefits of prefabricated buildings with the greatest efficiency. Financial efficiency plays an increasingly important role in the entire operation process, increasing the efficiency. Technological progress and the accumulation of management experience in the development process have promoted a steady increase in operating efficiency. At this time, the government should provide policy subsidies to component vendors to encourage them to develop new technologies to reduce costs and increase profits. The government imposes penalties on material vendors who do not provide components for environmental maintenance.

\subsection{Development Stage}

In the rapid development stage of prefabricated buildings, the operating efficiency is further improved, the production process of prefabricated components is more refined and exemplary, and the cost is further reduced. The number of stakeholders who develop and purchase prefabricated buildings in the market has increased, and the external benefits generated by prefabricated buildings are digested by the relevant stakeholders who enjoy external benefits. The conversion efficiency is reduced, and the financial efficiency reaches its peak. After analysis, the government's incentives should be reduced at this stage, the incentives and punishments for component vendors should be reduced, and the government's incentives should gradually be replaced by market forces. At the same time, the government should focus its incentives on stimulating component vendors to innovate in component technology.

\subsection{Mature Stage}

After the first two stages of development, the operating efficiency of prefabricated buildings has reached the highest level, and the technology is mature. The incremental benefits brought by the provision of prefabricated components exceed the incremental costs. All the material component manufacturers actively produce and provide components. The positive external effects generated by all the prefabricated buildings on the market are digested by consumers. The government's financial strength has reached the lowest level, the financial efficiency has gradually become zero, and the conversion efficiency is borne by the existing ordinary building inventory. According to the analysis in Figure 6, the three incentive policies of a solid or weak government will not change the behavior of component vendors, and ultimately achieve a state where component vendors take the initiative to provide components. The government does not need incentives to be completely regulated by the market.

\section{Conclusions, Deficiencies and Inspiration}

The development of prefabricated buildings is inseparable from the support of the relevant stakeholders. In the context of significant positive externalities, the government's behavior determines the development process of prefabricated buildings. When analyzing the relevant stakeholders that affect the development of prefabricated buildings, a comprehensive analysis must be carried out, not only considering the influence of direct actors such as supply and demand but also the influence of indirect actors. In the future, the development of prefabricated buildings must be the direction of incremental cost reduction, an incremental revenue increase, and an operational efficiency increase.

This article analyzes the development process of prefabricated buildings from the perspective of the government and component vendors. In the design part of the article model, we can find that the government's macro-control is the binding force for companies to enter the market, and it is also the critical force for component vendors to change their attitudes from providing ordinary materials to providing components. In the development process of prefabricated buildings, technological progress and cost reduction are the core of the development process, and the government's incentive policies are used as auxiliary forces to stimulate the development of prefabricated buildings. At different stages, government policies on incentives and penalties should have their focus. In the initial stage, to 
encourage component vendors to enter the market, the government should adopt incentive policies such as fiscal subsidies, tax reductions, and exemptions. In the development stage, the cost reduction allows component manufacturers to produce components independently. Therefore, the government's main goal at this stage is to suppress the provision of ordinary materials, which can be achieved using increasing taxes and fines. In the maturity stage, the reduction in costs and the technology maturity make component manufacturers profitable and exceed the profits of providing ordinary materials. At this time, the government can gradually withdraw from the market and play a decisive role in the market.

Based on the above analysis, it is concluded that the incremental cost seriously affects the development stage of prefabricated buildings. In order to promote the development of prefabricated buildings, it is necessary to use BIM technology to optimize from component design, production, transportation, installation, and other aspects, while increasing the experience of management personnel and improving corresponding laws, regulations and incentive policies. At the same time, the digitization and modeling ideas are more deeply implemented into the production of prefabricated components to achieve the goal of the rapid maturity of prefabricated buildings.

Through the analysis of the article, we have concluded that the development of prefabricated buildings can be promoted by adjusting the behavior of component suppliers. However, we only analyze the different behavior choices of component vendors in the development stage of prefabricated buildings under the macro background of government control at the theoretical level. In the following research, we can start from the actual construction projects and the deterministic government policies, increase the specific amount of government subsidies and fines, and quantitatively analyze the actual case of the model.

Author Contributions: P.Y. proposed the topic, designed the research content, and revised the final version of the paper. H.L. participated in revising and editing the paper. All authors have read and agreed to the published version of the manuscript.

Funding: This research was funded by Program of Shanghai Planning Office of Philosophy and Social Science of China (No. 2020BGL023).

Institutional Review Board Statement: Not applicable.

Informed Consent Statement: Not applicable.

Data Availability Statement: Not applicable.

Conflicts of Interest: The authors declare no conflict of interest.

\section{References}

1. Wang, B.; Yang, H. On the Internalization of Positive Externalities and their Performance-Comparison of Pigou and Coase's Internalization Theory of Positive Externalities. Southeast Acad. 2002, 6, 158-165.

2. Zhang, X. Analysis on the Reasons for the High Cost of Prefabricated Building. Intell. City 2019, 5, 25-26.

3. Chen, Y.; Lin, S.; Shi, Y. Evolutionary Game on Incentive Policy for Prefabrication. J. Civil Eng. Manag. 2018, 35, 155-160.

4. Chen, Q.; Liu, P.; Chen, C. Evolutionary Game Analysis of Government and Enterprises During Promotion Process of Prefabricated Construction. J. Interdiscip. Math. 2017, 20, 1587-1593. [CrossRef]

5. Wang, Z.; Zhang, Q.; You, W. An Evolutionary Game and Simulation Study on Government Incentive Strategy of Prefabricated Buildings. Syst. Eng. 2019, 37, 151-158.

6. Li, X.; Wang, C.; Alashwal, A. Game Analysis on Prefabricated Building Evolution Based on Dynamic Revenue risks in China. J. Clean. Prod. 2020, 267, 121730. [CrossRef]

7. Zhou, J.; Ren, D. A Study on the Distribution of Externality Benefits of Prefabricated Buildings-Based on Bargaining Game. J. Eng. Manag. 2019, 33, 19-24.

8. Zhou, J.; Ren, D. A Hybrid Model of External Environmental Benefits Compensation to Practitioners for the Application of Prefabricated Construction. Environ. Impact Assess. Rev. 2020, 81, 106358. [CrossRef]

9. Feng, T.; Tai, S.; Sun, C. Study on Cooperative Mechanism of Prefabricated Producers Based on Evolutionary Game Theory. Math. Probl. Eng. 2017. [CrossRef]

10. Han, Y.; Skibniewski, M.J.; Wang, L. A Market Equilibrium Supply Chain Model for Supporting Self-manufacturing or Outsourcing Decisions in Prefabricated Construction. Sustainability 2017, 9, 2069. [CrossRef] 
11. Tang, H.; Cao, J.; Xu, S.; Han, C. Analysis on BIM Application Cooperation Behaviors in Integrated Facility Management Organization Based on Evolutionary Game Theory. Ind. Eng. Manag. 2020, 25, 1-8.

12. Ma, X. Principles of Economics; Zhu, Z., Translator; The Commercial Press: Beijing, China, 2009.

13. Li, M.; Wu, W.; Wu, G. Promotion Mechanism of the Green Building Based on the Stakeholder Theory from the Perspective of Game Theory. J. Civil Eng. Manag. 2017, 34, 20-26.

14. Xu, L.; Dong, L.; Yin, J. Research on the Countermeasures for Promoting the Implementation of Green Construction from the Perspective of Cost Benefit Analysis. Constr. Econ. 2016, 37, 106-109.

15. Zheng, S. Post-appraisal and Path Selection of Green Building Based on Perspective of Externality. J. Eng. Manag. 2014, 28 , 17-21.

16. Liu, H.D.; Yao, P.B.; Wang, X.X. Research on the Peer Behavior of Local Government Green Governance Based on SECI Expansion Model. Land 2021, 10, 472. [CrossRef]

17. Sang, P.; Wang, Y.; Zhang, L. Co-evolutionary Simulation Analysis of Multiple Stakeholders in the Development of Prefabricated Buildings. J. Civ. Eng. Manag. 2019, 36, 17-24+31.

18. Pan, F.; Wang, L. Research on Determination Mechanism of Two-Person Evolutionary Game Strategy. Oper. Res. Manag. Sci. 2018, 27, 22-30.

19. Song, Q.; Jiang, P.; Zheng, S. Application of Evolutionary Game Theory in Safety Management of Chemical Production. Processes 2020, 8, 472. [CrossRef] 